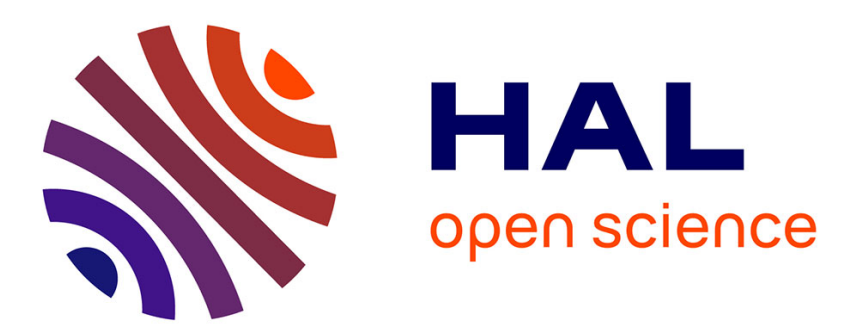

\title{
A microfluidic biochip for the nanoporation of living cells
}

\author{
Claire Dalmay, Julien Villemejane, Vanessa Joubert, Aude Silve, Delia \\ Arnaud-Cormos, Olivier Français, Lluis M Mir, Philippe Lévêque, Bruno Le \\ Pioufle
}

\section{To cite this version:}

Claire Dalmay, Julien Villemejane, Vanessa Joubert, Aude Silve, Delia Arnaud-Cormos, et al.. A microfluidic biochip for the nanoporation of living cells. Biosensors and Bioelectronics, 2011, 26 (12), pp.4649-4655. 10.1016/j.bios.2011.03.020 . hal-00674584

\section{HAL Id: hal-00674584 \\ https://hal-unilim.archives-ouvertes.fr/hal-00674584}

Submitted on 16 Feb 2013

HAL is a multi-disciplinary open access archive for the deposit and dissemination of scientific research documents, whether they are published or not. The documents may come from teaching and research institutions in France or abroad, or from public or private research centers.
L'archive ouverte pluridisciplinaire HAL, est destinée au dépôt et à la diffusion de documents scientifiques de niveau recherche, publiés ou non, émanant des établissements d'enseignement et de recherche français ou étrangers, des laboratoires publics ou privés.

$$
\text { Copyright }
$$




\title{
A microfluidic biochip for the nanoporation of living cells
}

\author{
Claire Dalmay $^{\mathrm{a}}$, Julien Villemejane ${ }^{\mathrm{a}, \mathrm{b}, \mathrm{c}}$, Vanessa Joubert ${ }^{\mathrm{b}, \mathrm{c}}$, Aude Silve ${ }^{\mathrm{b}, \mathrm{c}}$, Delia Arnaud- \\ Cormos $^{\mathrm{d}}$, Olivier Français ${ }^{\mathrm{a}}$, Lluis Mir ${ }^{\mathrm{b}, \mathrm{c}}$, Philippe Leveque ${ }^{\mathrm{d}}$, Bruno Le Pioufle ${ }^{\mathrm{a}^{*}}$ \\ ${ }^{a}$ SATIE UMR CNRS 8029, Institut d'Alembert, ENS Cachan, 61 av President Wilson, F-94835 Cachan, France \\ ${ }^{b}$ UMR CNRS 8203, Institut Gustave-Roussy, 114 rue Edouard. Vaillant, F-94805 Villejuif, France \\ ${ }^{c}$ Univ Paris-Sud, F-94805 Villejuif, France \\ 'XLIM UMR 6172 Limoges University/CNRS, 123 avenue A. Thomas, F-87060 Limoges, France
}

*corresponding author : e-mail: bruno.lepioufle@satie.ens-cachan.fr, Tel: +33 14740 77 36, Fax: +33 147402065

\begin{abstract}
This paper deals with the development of a microfluidic biochip for the exposure of living cells to nanosecond pulsed electric fields (nsPEF). When exposed to ultra short electric pulses (typical duration of 3 to $10 \mathrm{~ns}$ ), disturbances on the plasma membrane and on the intra cellular components occur, modifying the behavioral response of cells exposed to drugs or transgene vectors. This phenomenon permits to envision promising therapies. The presented biochip is composed of thick gold electrodes that are designed to deliver a maximum of energy to the biological medium containing cells. The temporal and spectral distributions of the nsPEF are considered for the design of the chip. In order to validate the fabricated biochip ability to orient the pulse towards the cells flowing within the exposition channels, a frequency analysis is provided. High voltage measurements in the time domain are performed to characterize the amplitude and the shape of the nSPEF within the exposition channels and compared to numerical simulations achieved with a 3D Finite-Difference Time-Domain code. We demonstrate that the biochip is adapted for $3 \mathrm{~ns}$ and $10 \mathrm{~ns}$ pulses and that the nsPEF are homogenously applied to the biological cells regardless their position along the microfluidic channel. Furthermore, biological tests performed on the developed microfluidic biochip permit to prove its capability to permeabilize living cells with nanopulses. To our knowledge, we report here the first successful use of a microfluidic device optimized for the achievement and real time observation of the nanoporation of living cells.
\end{abstract}

Keywords : Nanosecond pulsed electric field (nsPEF), microfluidic, biochip, biological cells, nanoporation

\section{Introduction}

The effects of short and intense electric fields on biological cells have been studied for a long time as they are known to induce disturbances on the plasma membrane which can become permeable to various molecules (Tsong 1991). This temporary permeabilization of the plasma membrane allows genes or drugs entering into the cell cytosol. This technique is very attractive in various applications such as electrochemotherapy (Marty et al. 2006; Mir et al. 2006), cutaneous and subcutaneous tumour nodule treatments (Mir et al. 1998), evaluation of the cytotoxicity of nonpermeant or poorly permeant anticancer drugs (Labanauskiene et al. 2007), gene electrotransfer to various animal tissues (Andre and Mir 2004; Andre et al. 2008) and latterly with in vivo tests (Gothelf and Gehl 2010; Heller and Heller 2006).

More recently, the development of generators allowing to reach very short and high voltage pulses, in the range of 3 to $10 \mathrm{~ns}$ with intensities between 20 to $150 \mathrm{kV} / \mathrm{cm}$, has opened a new important investigation field (Buescher et al. 2004; Vernier et al. 2004). Different works have reported about the effects on animal cells of these kinds of pulses, commonly named nanosecond pulsed electric fields (nSPEF). More precisely, it has been shown that the gene electrotransfection efficiency can be improved by nsPEF exposure, also called nanoporation, (Beebe et al. 2003) and that disturbances on the cell membrane could be sufficient to render it permeable to small molecules, such as propidium iodide (Ibey et al. 2009; Vernier et al. 2006). Beyond their potential effects on the cell membrane, these nsPEF show a great interest because they also offer the possibility to disturb the intra cellular structures and functions (Beebe and Schoenbach 2005).

However, the mechanisms implied in the effects of nsPEF on living cells remain still misunderstood. This is mainly due to the lack of real-time visualization and monitoring systems during nsPEF application on biological cells. 
Commercial electroporation chambers or cuvettes are commonly used to apply nanosecond pulses on living cells (Kenaan et al. 2010; Vernier et al. 2006), but are applied without any possibility to visualize cells in real time during the pulse applications which renders difficult the study of their effect.

In parallel, recent developments of microtechnologies and microfluidics techniques permit consideration of the design and fabrication of new innovative tools for biology. The main benefits of these technologies consist in their miniaturization and parallelization capabilities, as well as real-time observation in the case where transparent materials are used for the device fabrication. In the case of electroporation, miniaturized electrodes permit to expose cells on a chip to microsecond duration pulses (typically $100 \mu \mathrm{s}$ ) and intense electric fields (typically $1 \mathrm{kV} / \mathrm{cm}$ ) (Huang and Rubinsky 2001; Krishnaswamy et al. 2007; Le Pioufle et al. 2000; Lee et al. 2009; Wang et al. 2009). However, the delivery of the nsPEF (typically 3-10 nanoseconds, $20-45 \mathrm{kV} / \mathrm{cm}$ ) to the cells without deformation of spectral and temporal contents requires a specific design.

In this context, the work presented in this paper describes the design, fabrication and characterization of a miniaturized device specifically optimized for nsPEF exposure of living cells. The proposed device permits the realtime visualization of the nanoporation of cells, under fluorescent microscopy, thanks to the transparency of exposure channels. An electrical characterization of the biochip supported by frequency and time domain measurements and simulations is proposed. Biological characterizations of the cells exposed on the chip to $10 \mathrm{~ns}$ pulsed electric fields using a florescent dye are carried out.

The development of such microfluidic devices optimized for the real-time visualization of the effect of nsPEF on living cells is of prime importance as potentially, their use might provide (a) new knowledge on the nanoporation effects (b) high throughput production of permeabilized cells for further therapeutic uses as drug or gene insertion.

\section{Materials and Methods}

\subsection{Design methodology}

The biochip is composed of a $50 \mu \mathrm{m}$ thick SU8 microfluidic channel including thick gold electrodes with a typical thickness of $25 \mu \mathrm{m}$, in which cells suspended in a biological medium are injected. Gold is chosen as material for the electrodes because of its excellent electrical properties and biocompatibility (Dalmay et al. 2010).

The biochip is designed in such a way that the pulsed electric field is absorbed and dissipated mainly in the biological medium placed between the electrodes within which cells to be treated are flowed. To do so, impedance matching is necessary between the generator, the transmission line and the nanoporation biochip.

Considering the frequency spectrum of the applied pulses (typically $0-200 \mathrm{MHz}$ ), the electrical biochip behavior is mainly determined by the properties of the medium flowing within the microfluidic channel. It can be described by a parallel CG model, where $\mathrm{C}$ and $\mathrm{G}$ represent respectively the conductance and the capacitance of the biological medium (1).

$$
C=\varepsilon_{o} \varepsilon_{r} \frac{h \cdot L}{d} \text { and } G=\sigma \frac{h \cdot L}{d}
$$

where $\sigma$ and $\varepsilon_{\mathrm{r}}$ represent respectively the conductivity and the relative permittivity of the biological solution, $\mathrm{d}$ corresponds to the gap between the electrodes containing the medium, $\mathrm{h}$ is the thickness of the microchannel and $\mathrm{L}$ the length of electrode in contact with the medium into the channel.

The impedance $Z_{\mathrm{e}}$ of this model (2) has to be matched to the impedance of nsPEF generator $\left(Z_{\mathrm{g}}=50 \Omega\right)$ in order to (a) deliver a maximum of energy to the biological medium, (b) avoid reflections of the nsPEF backwards to the generator, (c) avoid temporal distortions of the applied nsPEF.

$$
Z_{e}=\frac{1}{G+j C \omega}=\frac{d}{A\left(\sigma+j \varepsilon_{0} \varepsilon_{r} \omega\right)}
$$

where $\mathrm{A}=\mathrm{L} \times \mathrm{h}$ represents the area of the electrical current density. Considering the conductivity $(\sigma=1 \mathrm{~S} / \mathrm{m})$ and the relative permittivity $\left(\varepsilon_{\mathrm{r}}=78\right)$ of the used biological media (see section 2.4$)$, a transition frequency appears: 


$$
f_{t}=\frac{\sigma}{2 \pi \varepsilon_{0} \varepsilon_{r}}=231 M H z
$$

Regarding that the impedance has to be matched to $\mathrm{Zg}=50 \Omega$ for most of the spectrum of the applied nsPEF, we chose to optimize the impedance mostly from continuous up to this transition frequency $f_{t}$ where most of the energy of the applied nsPEF is concentrated.

We have considered a distance gap (d) between the electrodes set to $150 \mu \mathrm{m}$, a height (h) for the SU8 microfluidic channels set to $50 \mu \mathrm{m}$ and a thickness (t) for the electrodes fixed to $25 \mu \mathrm{m}$. The chosen value for the thickness of gold electrodes $(\mathrm{t}=25 \mu \mathrm{m})$ represents a good compromise between technical constraints and homogeneity of the field across the whole microfluidic channel. Then, the length $(\mathrm{L})$ of the electrodes has to be $60 \mathrm{~mm}$. As the biochip electrodes are based on a coplanar line model with two parallel microchannels, their length has thus been set to 30 $\mathrm{mm}$.

\subsection{Fabrication process of the microfluidic biochip}

The fabrication process starts with a commercial quartz substrate metalized with a 10nm chromium and a $150 \mathrm{~nm}$ gold layer (ACM, France) and is used as the main support for transparent and planar surfaces at the end of the process. From this seed layer, electroplating of $25 \mu \mathrm{m}$ gold electrodes is achieved using an electrolytic bath based on potassium aurocyanure $\left(\mathrm{KAu}(\mathrm{CN})_{2}\right)$. Then a standard UV photolithography using a commercial photoresist (S1805, MicroChem) is used to define the electrode shapes. Removal of the excess gold is made on the different parts of the device by wet etching with a solution based on Potassium Iodide. Then the Cr seed layer is chemically etched. After the removal of the photoresist and the cleaning of the wafer by successive baths of acetone, ethanol and water combined with ultrasonic steps, the microfluidic channels are defined by a UV photolithography of a transparent commercial photoresist, which allows reaching a high aspect ratio (SU8-2025, MicroChem). The SU8 layer is $25 \mu \mathrm{m}$ thick to reach the total thickness of the microfluidic channel set to $50 \mu \mathrm{m}$. To finish, the biochip is packaged using a PDMS (Sylgard ${ }^{\circledR} 184$ Silicone Elastomer Kit, Dow Corning) membrane. This layer is bonded to the SU8 resist using a silanization process based on (3-Aminopropyl)trimethoxysilane (Aldrich) and methanol mixture.

Fig. 1 (a) presents the designed microfluidic biochip with actual measured dimensions and Fig. 2 shows a profilometer measurement of the microfluidic biochip. A photograph of the packaged microfluidic biochip is shown on Fig. 1 (b). The measured gap between electrodes was $d=130 \mu \mathrm{m}$, the thickness obtained for the channel is $\mathrm{h}=$ $47 \mu \mathrm{m}$ (Fig. 2) and the length of electroplating electrodes is $\mathrm{L}=33 \mathrm{~mm}$. Considering the equation (2), the equivalent impedance at low frequencies of the two parallel microchannels is $42 \Omega$.

\section{Insert Fig. 1}

Insert Fig. 2

\subsection{Electrical Characterization}

\subsubsection{Numerical modeling}

Assuming the parameters given in the previous section, the biochip is realistically modeled. A FDTD code (Finite Difference Time Domain) (Leveque et al. 2004; Leveque et al. 1992; Taflove and Hagness 2005; Yee 1966) is used to perform the numerical analysis. The analyzed structure is composed of the biochip whose microfluidic channels are filled with the biological medium. This FDTD modelling predicts the spatial and temporal evolutions of the EM fields within the biochip exposed to nsPEF.

The biochip structure, Fig. 1 (a), is entirely meshed using classical Yee (Yee 1966) elementary cells of 3D parallelepiped shape. In order to model the microfluidic channels as realistically possible, a non-uniform mesh is used. A grid resolution $(\Delta \mathrm{x}, \Delta \mathrm{y}$ and $\Delta \mathrm{z})$ of $200 \mu \mathrm{m} \times 13 \mu \mathrm{m} \times 12 \mu \mathrm{m}$ is used in the microfluidic channels and electrodes area. Otherwise, a large grid step of $200 \mu \mathrm{m} \times 500 \mu \mathrm{m} \times 100 \mu \mathrm{m}$ is considered. The time resolution is 
equal to 0.026 ps. Each simulation requires 160000 time iterations taking approximately 5 hours to perform on a NEC SX-8 computer cluster.

In addition to the geometrical dimensions, each elementary cell is defined by the electromagnetic properties, i.e. permittivity $\left(\varepsilon_{\mathrm{r}}\right)$ and conductivity $(\sigma)$, of the associated material. The considered biological medium properties are $\varepsilon_{\mathrm{r}}$ $=78$ and $\sigma=1 \mathrm{~S} / \mathrm{m}$. The electrodes are modeled as perfect conductors. For the quartz substrate, the SU8 and the PDMS, the permittivity is equal to $3.75,3.58$ and 2.7 , respectively. The electromagnetic field is modeled through a coaxial cable of $50 \mathrm{ohms}$ impedance and an SMA connector whose outputs are directly soldered on the biochip pads. Classical Perfectly Matched Layers (PML) are used to limit the computational domain (Berenger 1996).

The numerical analysis performed with the FDTD tool provides the electric field distribution in the microfluidic channels, the reflection coefficient $\left(\mathrm{S}_{11}\right)$ and the biochip input impedance.

\subsubsection{Experimental setup \\ 2.3.2.1. Frequency domain}

The biochip is experimentally characterized in the frequency domain with its microfluidic channels filled with a biological medium. The latter electromagnetic properties are measured at room temperature using a dielectric probe (85070E Dielectric probe kit, Agilent, USA) connected to a vector network analyzer (VNA 8753E, HP, USA). The measured electrical conductivity and relative permittivity of the biological medium are, at low frequencies, equal to $1 \mathrm{~S} / \mathrm{m}$ and 78 , respectively. The VNA is also used to measure the biochip reflection coefficient $\left(\mathrm{S}_{11}\right.$ parameter). The impedance is further computed from the reflection coefficient.

\subsubsection{Time domain}

Fig. 3 shows the set-up used for the time domain characterization of the microfluidic biochip exposed to highvoltage (HV) nsPEF. The exposure set-up is composed of an nsPEF generator, coaxial transmission lines and the biochip which allows delivering the pulses to the biological medium.

Two types of nsPEF are applied and characterized. The first type is provided by a HV generator (FPG 10-1SM10, FID Technology, Germany) which allows delivering $10 \mathrm{~ns}$ duration pulses with adjustable amplitude up to $10 \mathrm{kV}$. The second type is obtained by HV generator (Horus-Laser HT, France) which can deliver 3 ns duration pulses with adjustable amplitude up to $3 \mathrm{kV}$ peak-to-peak (E1 Amari et al. 2010; Vergne et al. 2008).

In order to characterize the incident and reflected signals in the exposure set-up, a tap-off (245 NMFFP-100, Barth Electronics Technology, USA) is connected between the generator and the biochip using two transmission lines (RG 214 cable). The tap-off is a three-port device. The mainline, i.e. nsPEF-biochip line, impedance is $50 \mathrm{ohms}$ whereas the measurement port, i.e. oscilloscope, impedance is $4950 \mathrm{ohm}$, allowing the voltage measurement with a 1:100 ratio. The electrical delay introduced by the two transmission lines (1 $\mathrm{m}$ and $2 \mathrm{~m}$ long) allows obtaining the incident and reflected waves (Kenaan et al. 2010).

The applied voltage across the biochip electrodes is measured by a HV probe (2440, Barth Electronic Technology, USA). The probe has a large frequency bandwidth $(6 \mathrm{GHz})$ and is designed to have the output terminated into a $50 \mathrm{ohm}$ system with a voltage ratio of 1:10. For the measurements, the two conductor pins of the probe are placed in direct contact with the input or output of the gold electrodes.

The measured pulses are displayed on a digital storage oscilloscope (DSO, TDS 6124C, Tektronix, USA). The DSO has: $12 \mathrm{GHz}$ frequency bandwidth, $50 \mathrm{ohms}$ input impedance and is limited to $5 \mathrm{~V}$ root mean square (RMS) voltage intensities. Therefore, $26 \mathrm{~dB}$ high voltage attenuators (Model 142, Barth Electronics, USA) are connected between the tap-off, the HV probe and the DSO.

\section{$\underline{\text { Insert Fig. } 3}$}

\subsection{Biological experiments protocol}

Biological experiments are carried out with DC-3F cells (Chinese hamster fibroblast lung cells). The cells are grown in Minimum Essential Medium (Invitrogen, Cergy-Pontoise, France) supplemented with $10 \%$ fetal bovine serum (Invitrogen), $500 \mathrm{U} / \mathrm{ml}$ penicillin, $500 \mu \mathrm{g} / \mathrm{ml}$ streptomycin (Invitrogen) defined as complete medium. Cultures are maintained in a humidified atmosphere with $5 \% \mathrm{CO} 2$ at $37^{\circ} \mathrm{C}$. Cells are routinely passed every two days. 
For the biological experiments, cells are rinsed in PBS (Phosphate Buffered Saline) and harvested by Tryple Express (Invitrogen). After centrifugation, the cell pellet is suspended in S-MEM solution (typical concentration of cells around $10^{6} / \mathrm{ml}$ ).

Cells are injected into the microfluidic channels using a micro syringe pump controller (Micro ${ }^{\mathrm{TM}}$ from World Precision Instruments), which is connected to Teflon tubing (internal diameter $0.56 \mathrm{~mm}$ ) attached to a $1 \mathrm{ml}$ syringe (Terumo Medical Corporation). The tubing is then inserted into the inlet of the microfluidic access on top of the PDMS cover.

In order to visualize the effect of nsPEF on living cells, a fluorescent dye named Propidium Iodide (PI) (SigmaAldrich, L'Isle-d'Abeau-Chesne, France) is added to the cell suspension (Bowman et al. 2010). A quantity of $20 \mu 1$ (at $1 \mathrm{mM}$ ) is added in $500 \mu \mathrm{l}$ of the cell suspension. If the plasma membrane is sufficiently disturbed when exposed to the nsPEF, the fluorescent dye enters into the cytosol of the cell which becomes fluorescent. Hence, by monitoring the fluorescence of exposed cells, one knows if the plasma membrane is affected by the nsPEF.

A negative control is performed showing that after the injection of cells in the microfluidic channel, no fluorescence appears without exposing cells to nsPEF.

After preparation, the cells are injected in the microfluidic network and exposed to trains of different number of pulses (171 or 271 pulses) varying their amplitude $(35$ or $45 \mathrm{kV} / \mathrm{cm})$. The duration of the applied nsPEF is set to 10 ns.

Viability tests are performed in order to confirm that the cells remain functional after exposure to nsPEF. For that purpose, two methodologies are followed a) cells are collected after being nanoporated on the biochip and exposed to Trypan blue $(0.2 \%)$, a dye that stains in blue the permeabilized cells (Tennant 1964) b) cells are loaded with a fluorescent dye named calcein (through 1 hour incubation with calcein-AM $(1 \mu \mathrm{M})$ at $\left.37^{\circ} \mathrm{C}\right)$ to show their subsequent permeabilization immediately after the nsPEF delivery, and they are also finally exposed to Trypan blue, still in place in the channel, 40 minutes after nsPEF exposure. Both results show a good viability of cells after the application of nsPEF.

\section{Results and Discussion}

\subsection{Electrical behavior}

\subsubsection{Frequency domain}

Fig. 4 presents the reflection coefficient $\left(S_{11}\right)$ and the real part of the impedance $Z_{e}$ obtained by FDTD simulation and measurements for the biochip. The simulated and measured results present a very good level of consistency. Fig. 4 (a) shows that a good impedance matching is obtained for frequencies up to $110 \mathrm{MHz}$ (where $\left|\mathrm{S}_{11}\right|<-10 \mathrm{~dB}$ i.e. less than $10 \%$ of the incident power is reflected). As observed in Fig. 4 (b), for low frequencies, the biochip impedance is purely resistive and mainly fixed by the conductivity value of the biological medium. The measured and simulated impedance values are around $40 \mathrm{ohms}$. This value is in accordance with the one obtained with the analytical model proposed in section 2.2 considering the dimensions of the fabricated biochip. It can be enhanced by adjusting the conductivity value of the biological medium.

For high frequencies, the dielectric component of the biological solution increases, therefore inducing a decrease of the biochip impedance. The impedance matching is thus less effective inducing a deformation in the shape of the applied pulses.

\section{Insert Fig. 4}

\subsubsection{Time domain}

Two types of nsPEF are applied to the microfluidic biochip: $10 \mathrm{~ns}$ duration pulses and 3 ns duration pulses. In Fig. 4 (c) (d), the voltage measurements, i.e. the generated and applied pulses, are presented. In order to test the limits of biochip voltage breakdown, the high voltage intensities are higher than those used in biological experiments. 
The FID Technology generator delivering $10 \mathrm{~ns}$ square shape pulses with a $5.9 \mathrm{kV}$ amplitude is used in the experimental set-up. As observed in Fig. 4 (c), the amplitude and duration (10 ns) of the generated and applied pulses present a good level of consistency. The rise time is slightly modified by the biochip impedance mismatch for high frequencies (good impedance matching is ensured up to about $110 \mathrm{MHz}$ ).

\section{3 ns square shape nsPEF measurements}

The Horus-Laser generator delivering $3 \mathrm{~ns}$ duration square shape pulses with a $1.77 \mathrm{kV}$ amplitude is used in the experimental set-up. As observed in Fig. 4 (d), the amplitude and duration (2.4 ns at half maximum) of the generated and applied pulses present a good level of consistency. The amplitude of the applied pulse is slightly lower than the generated pulse. This difference can be related to high frequency impedance mismatch of the biochip.

A similar rise time of $1.4 \mathrm{~ns}$ is obtained for both the generated and applied pulses. In the previous case (10 ns pulse duration), the rise time is shorter $(0.5 \mathrm{~ns})$. The fact that the biochip impedance spectrum does not fit to the impedance of the generator at high frequencies explains the increase of the rise time duration.

\section{Spatial-temporal distribution of applied $3 \mathrm{~ns}$ and $10 \mathrm{~ns}$ pulses}

Fig. 5 (spatial and temporal evolution of the electric field within the channel) illustrates the fact that the deformation of the nsPEF propagating along the microfluidic channel remains quite acceptable.

Indeed, as computed with the FDTD tool, the temporal waveform of the pulsed electric field is quite homogeneous along the microfluidic channel ( $\mathrm{z}$ axis), with an amplitude variation between temporal evolution curves that does not exceed $4 \%$ (case of $10 \mathrm{nS}$ pulses) or $6 \%$ (case of $3 \mathrm{nS}$ pulses). This ensures that cells are exposed to the same electric field regardless their location into the microfluidic channels. The spatial distribution of the electric field is thus quite consistent.

\section{$\underline{\text { Insert Fig. } 5}$}

\subsection{Biological experiments}

Experimental biological tests are performed with $10 \mathrm{~ns}$ duration pulses. A train of $171 \mathrm{nsPEF}$, square shaped, 10 ns duration is applied with a repetition frequency of $234 \mathrm{~Hz}$. A view (fluorescence or bright field microscopy) of cells within the microfluidic channel is recorded before and just after the application of nsPEF.

\section{Insert Fig. 6}

As shown on Fig. 6 (a) and (b) (where experimental conditions are set to 171 pulses, amplitude of $45 \mathrm{kV} / \mathrm{cm}$ for the electric field), cells fluoresce in red after the application of nsPEF, proving that PI introduces into the cytosol, due to the disturbance of the plasma membrane. Note that the observation is made with functional cells located in the white circles drawn on this figure (the flashy red spots which can be seen outside of these circles corresponding to Propidium Iodide residues from previous experiments. They were not considered for result exploitation).

Viability of cells submitted to nsPEF treatment was checked thanks to Trypan Blue test, as depicted in material and methods section. An average of $98 \pm 1 \%$ of exposed cells remains still alive 40 minutes after being exposed to nsPEF.

The number of nanopulses that were applied (171 or 271 pulses), as well as the amplitude of the electric field ( 35 $\mathrm{kV} / \mathrm{cm}$ or $45 \mathrm{kV} / \mathrm{cm}$ ) were tuned in order to confirm the effect of these parameters on the permeabilization ratio (different measurements are reported on the table in Fig. 6 (c)). As expected, the number of pulses and their amplitude both influence the level of permeabilization.

These preliminary characterizations of the effect of nanoporation on living cells, in particular on the permeabilization of the plasma membrane, were permitted thanks to the real time observation on the miniaturized biodevice. Deeper exploitation of this type of device will be conducted together with the development of new nsPEF generators (more flexibility in term of pulse duration, amplitude and frequency). Actual results demonstrate the 
capability of the developed microfluidic biochip to address nsPEF to the cells within the microchannel, permeabilizing their plasma membrane while keeping a reasonable level of viability.

\title{
4. Conclusion
}

A new microfluidic biodevice optimized for the nsPEF exposure of living cells has been proposed and characterized in this paper. Preliminary results showed the feasibility to use such a device for the study of the nanoporation of living cells, as it permits real-time visualization of the effect of nsPEF. Miniaturization of the exposure channel allows to investigate more intense field strength by reducing the gap between the electrodes.

In order to optimize the structure of the biodevice, the amplitude and the shape of the pulses delivered to the biological sample were precisely characterized. The matching frequency bandwidth of the microfluidic device impedance was measured and can be adjusted with the medium conductivity. The high voltage nsPEF measurements associated to the frequency characterization (110 MHz bandwidth) demonstrated the suitability of the developed device for $3 \mathrm{~ns}$ and $10 \mathrm{~ns}$ duration pulses biological experiments.

Biological tests were performed with the fabricated chip applying an electric field of $45 \mathrm{kV} / \mathrm{cm}$ to the biological cells. They showed that the nanoporation of living cells is effective. The microfluidic biochip ensures real time visualization and a good viability of biological samples.

The development of such biochips for the exposure of cells to nsPEF permits (a) the application of intense and short pulsed electric field, (b) the real-time visualization of nsPEF effect on cells, (c) the continuous treatment of cells in flux and (d) the conservation of the cell viability without contamination.

The understanding of biological mechanisms, which can occur during nanoporation of living cells, can be achieved by using this type of microfluidic device. To our knowledge, this study reports one of the first successful nanoporation of living cells performed and observed in real time on a microfluidic biochip.

\author{
Aknowledgments \\ This work was supported by grants from French National Agency through Nanoscience and Nanotechnology \\ Program (Nanopulsebiochip n ANR-08-NANO-024), CNRS, Institut Gustave Roussy, University Paris-Sud, ENS \\ de Cachan, PRES Universud and CNANO'Ile de France.
}




\section{References}

Andre, F., Mir, L.M., 2004. DNA electrotransfer: its principles and an updated review of its therapeutic applications. Gene Therapy 11, S33-S42.

Andre, F.M., Gehl, J., Sersa, G., Preat, V., Hojman, P., Eriksen, J., Golzio, M., Cemazar, M., Pavselj, N., Rols, M.P., Miklavcic, D., Neumann, E., Teissie, J., Mir, L.M., 2008. Efficiency of High- and Low-Voltage Pulse Combinations for Gene Electrotransfer in Muscle, Liver, Tumor, and Skin. Human Gene Therapy 19(11), 12611271.

Beebe, S.J., Schoenbach, K.H., 2005. Nanosecond pulsed electric fields: A new stimulus to activate intracellular signaling. Journal of Biomedicine and Biotechnology(4), 297-300.

Beebe, S.J., White, J., Blackmore, P.F., Deng, Y.P., Somers, K., Schoenbach, K.H., 2003. Diverse effects of nanosecond pulsed electric fields on cells and tissues. DNA and Cell Biology 22(12), 785-796.

Berenger, J.P., 1996. Three-dimensional perfectly matched layer for the absorption of electromagnetic waves. J. Comput. Phys. 127(2), 363-379.

Bowman, A.M., Nesin, O.M., Pakhomova, O.N., Pakhomov, A.G., 2010. Analysis of plasma membrane integrity by fluorescent detection of TI(+) uptake. J Membr Biol 236(1), 15-26.

Buescher, E.S., Smith, R.R., Schoenbach, K.H., 2004. Submicrosecond intense pulsed electric field effects on intracellular free calcium: mechanisms and effects. Plasma Science, IEEE Transactions on 32(4), 1563-1572.

Dalmay, C., Cheray, M., Pothier, A., Lalloué F., Jauberteau, M.O., Blondy, P., 2010. Ultra Sensitive Biosensor Based on Impedance Spectroscopy at Microwave Frequencies for Single Cell Analysis. Sens. Actuators A : phys., doi:10.1016/j-sna.2010.04.023.

El Amari, S., Kenaan, M., Merla, C., Vergne, B., Arnaud-Cormos, D., Leveque, P., Couderc, V., 2010. Kilovolt, Nanosecond, and Picosecond Electric Pulse Shaping by Using Optoelectronic Switching. Photonics Technology Letters, IEEE 22(21), 1577-1579.

Gothelf, A., Gehl, J., 2010. Gene Electrotransfer to Skin; Review of Existing Literature and Clinical Perspectives. Current Gene Therapy 10(4), 287-299.

Heller, L.C., Heller, R., 2006. In vivo electroporation for gene therapy. Human Gene Therapy 17(9), 890-897.

Huang, Y., Rubinsky, B., 2001. Microfabricated electroporation chip for single cell membrane permeabilization. Sensors and Actuators a-Physical 89(3), 242-249.

Ibey, B.L., Xiao, S., Schoenbach, K.H., Murphy, M.R., Pakhomov, A.G., 2009. Plasma Membrane Permeabilization by 60-and 600-ns Electric Pulses Is Determined by the Absorbed Dose. Bioelectromagnetics 30(2), 92-99.

Kenaan, M., El Amari, S., Silve, A., Merla, C., Mir, L.M., Couderc, V., Arnaud-Cormos, D., Leveque, P., 2010. Characterization of a $50 \mathrm{Ohm}$ Exposure Set-up for High Voltage Nanosecond Pulsed Electric Field Bioexperiments. Biomedical Engineering, IEEE Transactions on 58(1), 207-214.

Krishnaswamy, P., Kuthi, A., Vernier, P.T., Gundersen, M.A., 2007. Compact subnanosecond pulse generator using avalanche transistors for cell electroperturbation studies. Dielectrics and Electrical Insulation, IEEE Transactions on 14(4), 871-877.

Labanauskiene, J., Gehl, J., Didziapetriene, J., 2007. Evaluation of cytotoxic effect of photodynamic therapy in combination with electroporation in vitro. Bioelectrochemistry 70(1), 78-82. 
Le Pioufle, B., Surbled, P., Nagai, H., Murakami, Y., Chun, K.S., Tamiya, E., Fujita, H., 2000. Living cells captured on a bio-microsystem devoted to DNA injection. Materials Science \& Engineering C-Biomimetic and Supramolecular Systems 12(1-2), 77-81.

Lee, W.G., Demirci, U., Khademhosseini, A., 2009. Microscale electroporation: challenges and perspectives for clinical applications. Integrative Biology 1(3), 242-251.

Leveque, P., Dale, C., Veyret, B., Wiart, J., 2004. Dosimetric analysis of a 900-MHz rat head exposure system. IEEE Transactions on Microwave Theory and Techniques 52(8), 2076-2083.

Leveque, P., Reineix, A., Jecko, B., 1992. Modeling of dielectric losses in microstrip patch antennas - application of fdtd method. Electronics Letters 28(6), 539-541.

Marty, M., Sersa, G., Garbay, J.R., Gehl, J., Collins, C.G., Snoj, M., Billard, V., Geertsen, P.F., Larkin, J.O., Miklavcic, D., Pavlovic, I., Paulin-Kosir, S.M., Cemazar, M., Morsli, N., Rudolf, Z., Robert, C., O'Sullivan, G.C., Mir, L.M., 2006. Electrochemotherapy - An easy, highly effective and safe treatment of cutaneous and subcutaneous metastases: Results of ESOPE (European Standard Operating Procedures of Electrochemotherapy) study. Ejc Supplements 4(11), 3-13.

Mir, L.M., Glass, L.F., Sersa, G., Teissie, J., Domenge, C., Miklavcic, D., Jaroszeski, M.J., Orlowski, S., Reintgen, D.S., Rudolf, Z., Belehradek, M., Gilbert, R., Rols, M.P., Belehradek, J., Bachaud, J.M., DeConti, R., Stabuc, B., Cemazar, M., Coninx, P., Heller, R., 1998. Effective treatment of cutaneous and subcutaneous malignant tumours by electrochemotherapy. British Journal of Cancer 77(12), 2336-2342.

Mir, L.M., Gehl, J., Sersa, G., Collins, C.G., Garbay, J.R., Billard, V., Geertsen, P., Rudolf, Z., O’Sullivan, G.C., Marty, M., 2006. Standard operating procedures of the electrochemotherapy: Instructions for the use of bleomycin or cisplatin administered either systemically or locally and electric pulses delivered by the CliniporatorTM by means of invasive or non-invasive electrodes. Eur J Cancer S4, 14-25.

Taflove, A., Hagness, S.C., 2005. Computational electrodynamics : the finite-difference time-domain method, 3rd ed. Artech House, Boston.

Tennant, J.R., 1964. Evaluation of the trypan blue technique for determination of cell viability. Transplantation 2 , 685-694.

Tsong, T.Y., 1991. Electroporation of cell-membranes. Biophysical Journal 60(2), 297-306.

Vergne, B., Couderc, V., Leveque, P., 2008. A 30-kHz Monocycle Generator Using Linear Photoconductive Switches and a Microchip Laser. Photonics Technology Letters, IEEE 20(21-24), 2132-2134.

Vernier, P.T., Sun, Y.H., Gundersen, M.A., 2006. Nanoelectropulse-driven membrane perturbation and small molecule permeabilization. Bmc Cell Biology 7.

Vernier, P.T., Thu, M.M.S., Marcu, L., Craft, C.M., Gundersen, M.A., 2004. Nanosecond electroperturbation Mammalian cell sensitivity and bacterial spore resistance. Plasma Science, IEEE Transactions on 32(4), 1620-1625.

Wang, S.F., Chen, J.X., Chen, M.T., Vernier, P.T., Gundersen, M.A., Valderrabano, M., 2009. Cardiac Myocyte Excitation by Ultrashort High-Field Pulses. Biophysical Journal 96(4), 1640-1648.

Yee, K., 1966. Numerical solution of initial boundary value problems involving maxwell's equations in isotropic media. Antennas and Propagation, IEEE Transactions on 14(3), 302-307. 


\section{Figure captions}

Fig. 1. (a) Scheme of the designed microfluidic biochip; top and side views and (b) View of the microfabricated microfluidic biochip; full top view and zoom on the input microfluidic access.

Fig. 2 (a) Schematic 3D view of fabricated microfluidic biochip (arbitrary scale) and (b) Profilometer scan of the fabricated microfluidic biochip.

Fig. 3. Experimental set-up for high voltage nsPEF application and measurements.

Fig. 4. (a) Reflection coefficient (S11) and (b) real part of the impedance obtained by FDTD simulation and measurements for the biochip; the microchannels are filled with the biological medium. Voltage measurements of the generated and applied pulses on the biochip. Two types of nsPEF are characterized : (c) $10 \mathrm{~ns}$ and (d) 3 ns duration pulses.

Fig. 5. FDTD modelling of the spatial distribution of the voltage across the electrodes along the microfluidic channel. (a) 10 ns pulse, (b) 3 ns pulse. Top corner: superposition of curves at $\mathrm{x}=1 \mathrm{~mm}$ (channel inlet) and $\mathrm{x}=33 \mathrm{~mm}$ (channel outlet).

Fig. 6. Photographs of DC-3F cells inside the microfluidic channel of the biochip: (a) before and (b) after exposure to nsPEF (bright field imaging and fluorescence imaging - the studied cells are circled) - (c) Table of percentage of permeabilized cells depending both on the number and amplitude of applied nsPEF.

a
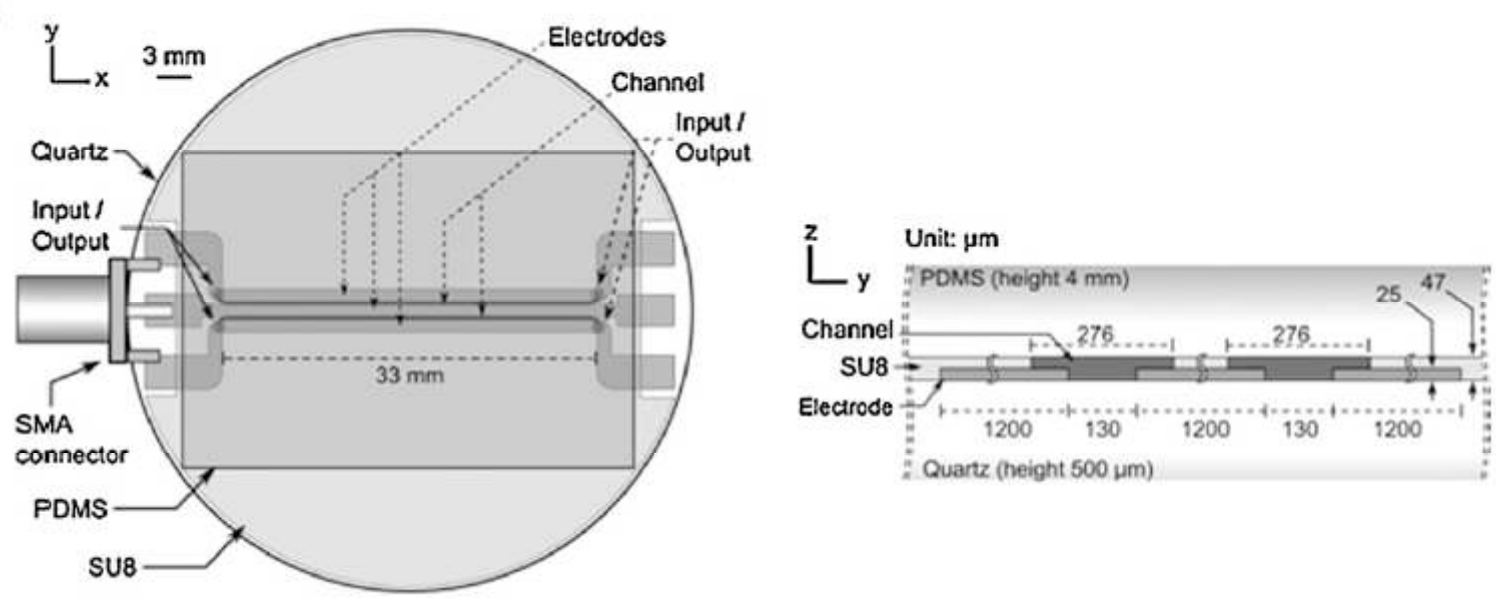

b
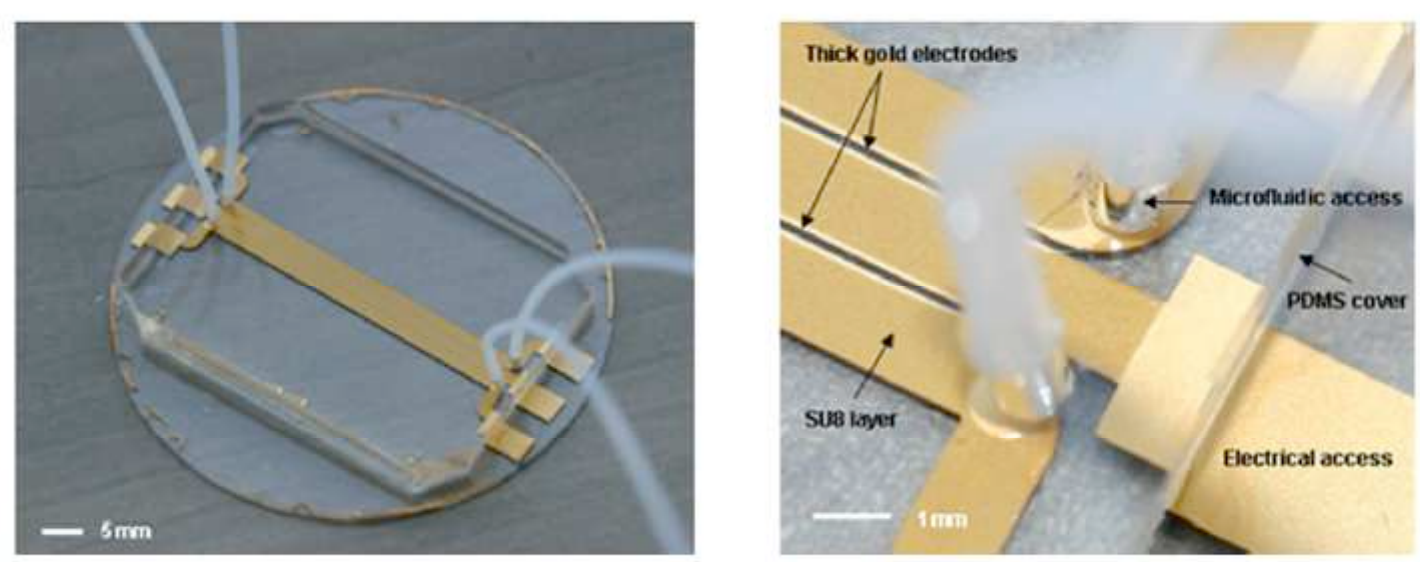

Fig 1 
a

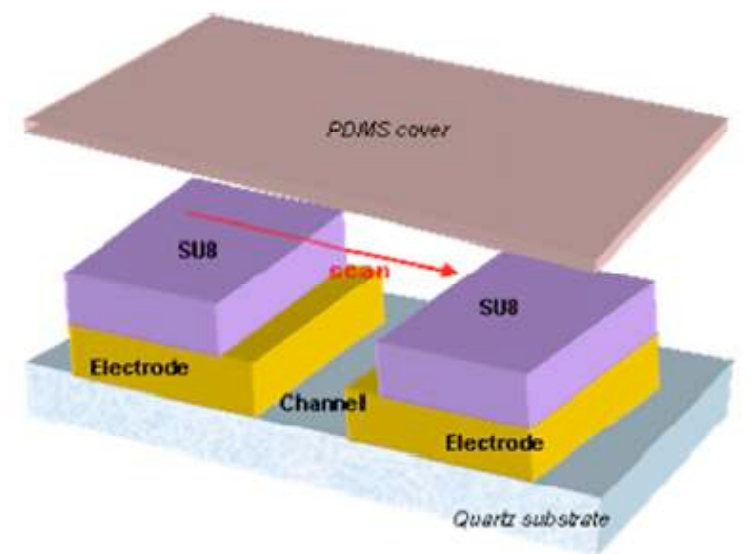

Fig 2
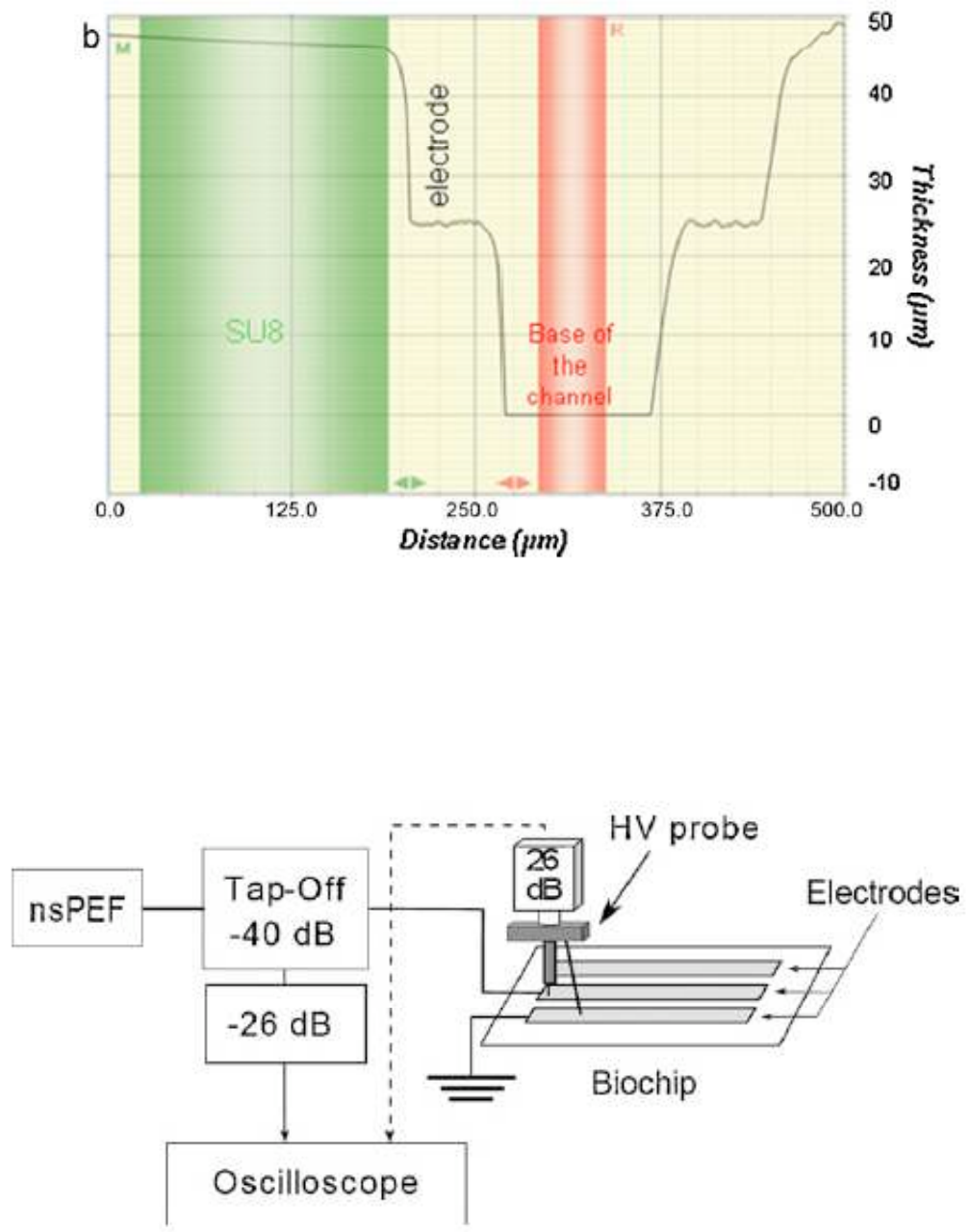

Fig 3 

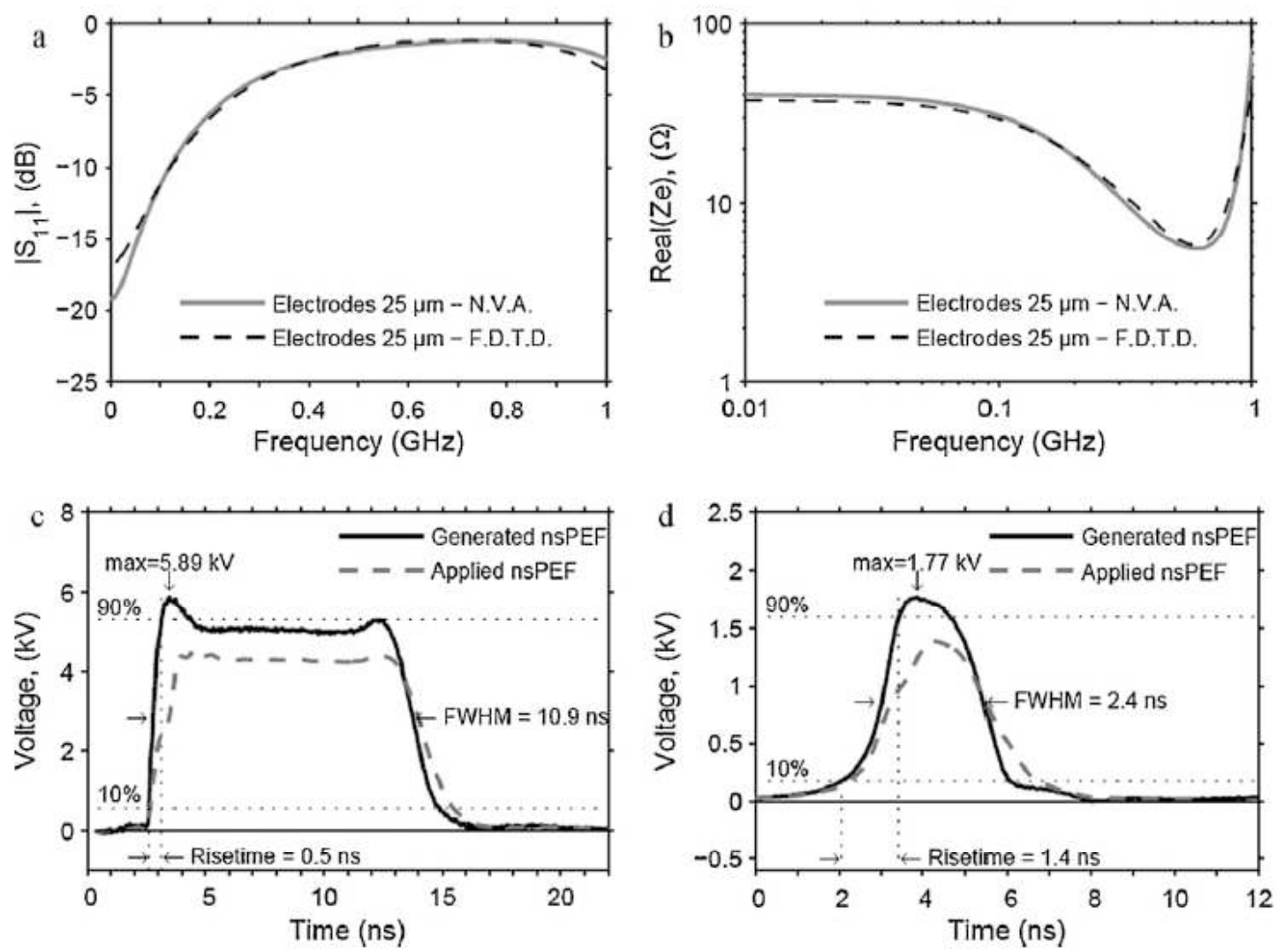

Fig 4
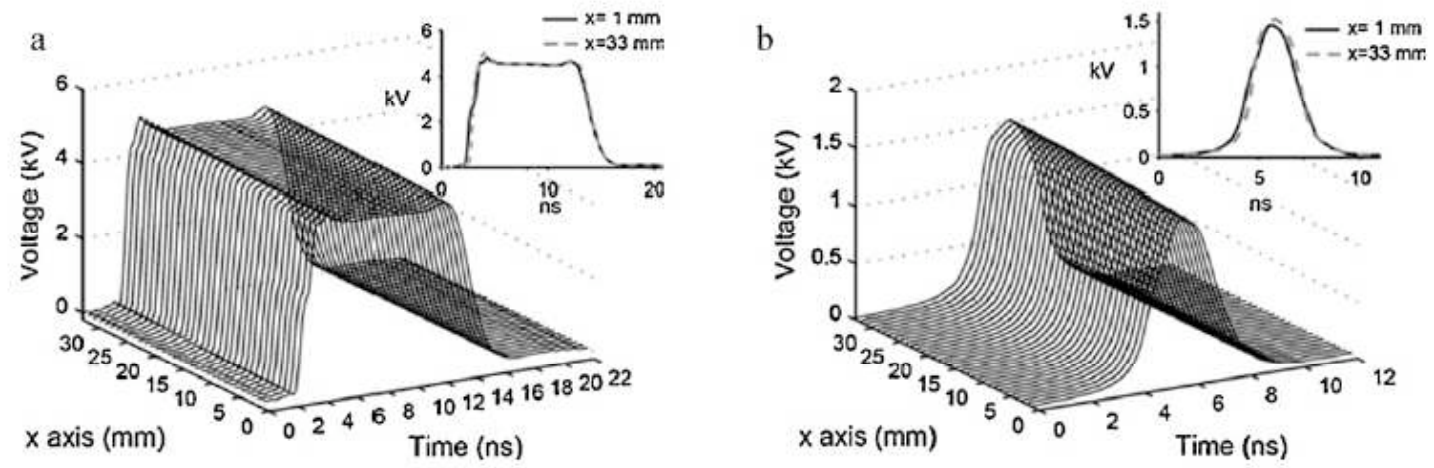

Fig 5 

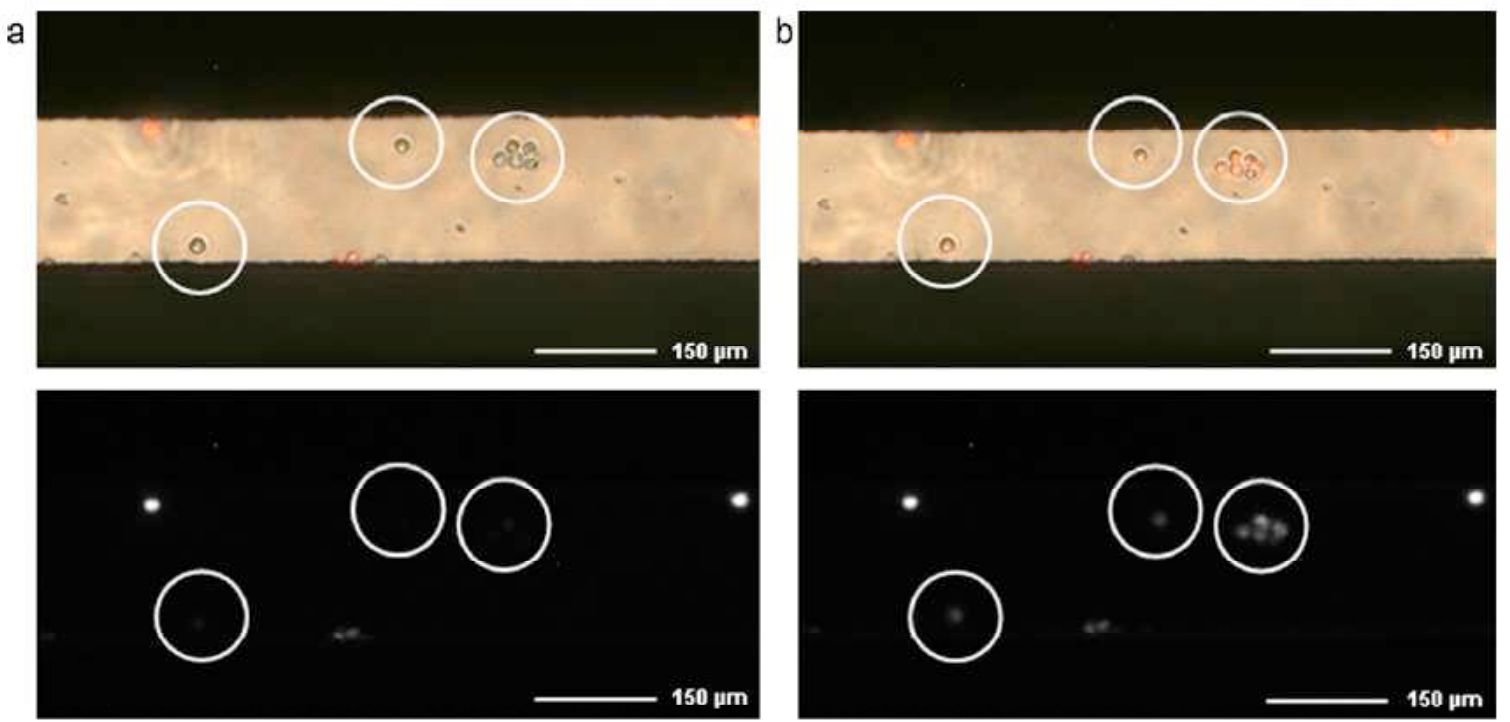

Before exposure

Afier $171 \mathrm{nsPEF}, 10 \mathrm{~ns}, 45 \mathrm{kV} / \mathrm{cm}$

\begin{tabular}{|c|c|c|c|}
\hline \multicolumn{3}{|c|}{ Conditions } & \multicolumn{2}{|c|}{} \\
\hline $\begin{array}{c}\text { Applied electric feld } \\
\text { (kViom) }\end{array}$ & Num ber of pulses & \multicolumn{2}{c|}{$\begin{array}{c}\text { of permeabilized } \\
\text { cells }\end{array}$} \\
\hline 35 & 171 & \multicolumn{2}{|c|}{$56( \pm 4)$} \\
\hline 45 & 171 & $71( \pm 6)$ & $85( \pm 7)$ \\
\hline 45 & 271 & $92( \pm 4)$ & $95( \pm 5)$ \\
\hline
\end{tabular}

Fig 6 